That said, Ventria, at least, seems to have learned from the mistakes of others. They are now growing transgenic pharma rice in a state (Kansas) where little-to-no rice is produced, which is also outside its traditional production area. No other rice is grown within nearly $500 \mathrm{~km}$ of their fields ${ }^{7}$. They use dedicated farm machinery and in transporting thei transgenic rice to processing. Processing and storage of rice is in a dedicated facility as well. Weedy red rice is the same species as cultivated rice, but it has not been reported to grow in the area of cultivation, therefore hybridization and introgression is not of concern and introgression rates are very low anyway in this species ${ }^{10}$.

So why worry? Scientifically, I have very few worries with regards to biosafety in this particular case. Ventria is indeed taking extraordinary measures to ensure transgene containment. USDA APHIS continues to evolve and has improved inspection frequency and procedures. I do

worry that, until we devalue the doctrine of adventitious presence, any slight detection of transgenes outside of their intended locales will be overblown beyond reason. In spite of Ventria's care, there is still a chance that vigilant people with advanced detection procedures will find something to report-regardless of real biosafety issues. Therefore, if we believe this to be true, Ventria (and any other company cultivating pharma crops in open fields) must perform perfectly year after year to avoid admixtures. In spite of the odds and current climate, I am cautiously optimistic that pharming rice in Kansas could be a model for other companies to follow.

But would they, and what issues lie beyond admixture? There are two absolute conditions to assure biosafety when pharming crop commodities (not counting Murphy's Law). The first requirement is extraordinary physical isolation and dedicated equipment. Still, there are limited numbers of suitably isolated sites that are available and conducive for rice production in the United States. Second, the pharma products must be safe for accidental consumption in bulk by wildlife and humans. For the latter, accidental bulk ingestion should be part of the standard regulatory package.

The bottom line for most people is a level of discomfort with open-air pharma production of any sort, and especially when it is in a grain crop that has been bred for palatability and nutrition (that is, begging to be eaten by humans and wildlife). It is hard to predict when and if this circumstance will change. In the meantime, the proposed rules are available for public comment for 45 days until November 24 .

\section{Neal Stewart Jr}

Department of Plant Sciences, University of Tennessee, Knoxville, TN 37996, USA.

e-mail:nealstewart@utk.edu

1. <http://federalregister.gov/OFRUpload/OFRData/200823584_PI.pdf>

2. Anonymous. Editorial. Nat. Biotechnol. 22, 133
(2004).

3. Fox, J.L. Nat. Biotechnol. 25, 367-368 (2007).

4. Stewart, C.N., Jr. Genetically Modified Planet Environmental Impacts of Genetically Engineered Plants (Oxford University Press, New York; 2004).

5. Miller, H.I. Nat. Biotechnol. 21, 480-481 (2003).

6. Ramessar, K. et al. Phytochem. Rev. 7, 579-592 (2008).

7. <http://www.aphis.usda.gov/brs/aphisdocs/06_27801r ea.pdf $>$

8. Pla, M. et al. Transgenic Res. 15, 219-228 (2006).

9. Yuan, J. et al. BMC Bioinformatics 8 Suppl 7, S6 (2007).

10. Stewart, C.N., Jr. Nat. Rev. Genet. 4, 806-817 (2003).

\title{
Coexistence in the EU-return of the moratorium on GM crops?
}

\section{To the editor:}

The decision of European Union (EU; Brussels) commissioner for environment, Stavros Dimas, to defer market approvals of maize Bt11 and 1507 against the recommendation of his scientific advisers is an indication that Europe remains in a state of quasi-moratorium regarding the cultivation of genetically modified (GM) crops. Here, we outline another challenge that threatens to paralyze the cultivation of GM crops in Europe: regulations on the coexistence of GM and non-GM crops.

As a last building stone of the restyled EU legal framework, the adopted coexistence policy aims to ensure that different cropping systems develop side by side without excluding any agricultural option. Because of the heterogeneity in farm structures, crop patterns and legal environments among member states, the European Commission (EC; Brussels) follows the subsidiarity principle for the implementation of legal coexistence frames ${ }^{1}$. According to this principle, coexistence should be handled by the lowest authority possible. In the following text, we use the example of $B t$ maize, a crop that expresses the insecticidal protein CrylAb from Bacillus thuringiensis in its tissues, to explore how national and/or regional coexistence regulations might affect the future adoption of $B t$ maize. At present, $B t$ maize is the only GM crop planted over a significant area in the EU (Fig. 1).

To ensure coexistence between cropping systems, member states are currently implementing or developing ex ante coexistence regulations and ex post liability schemes. In ex ante coexistence regulations, preventive on-farm measures are prescribed

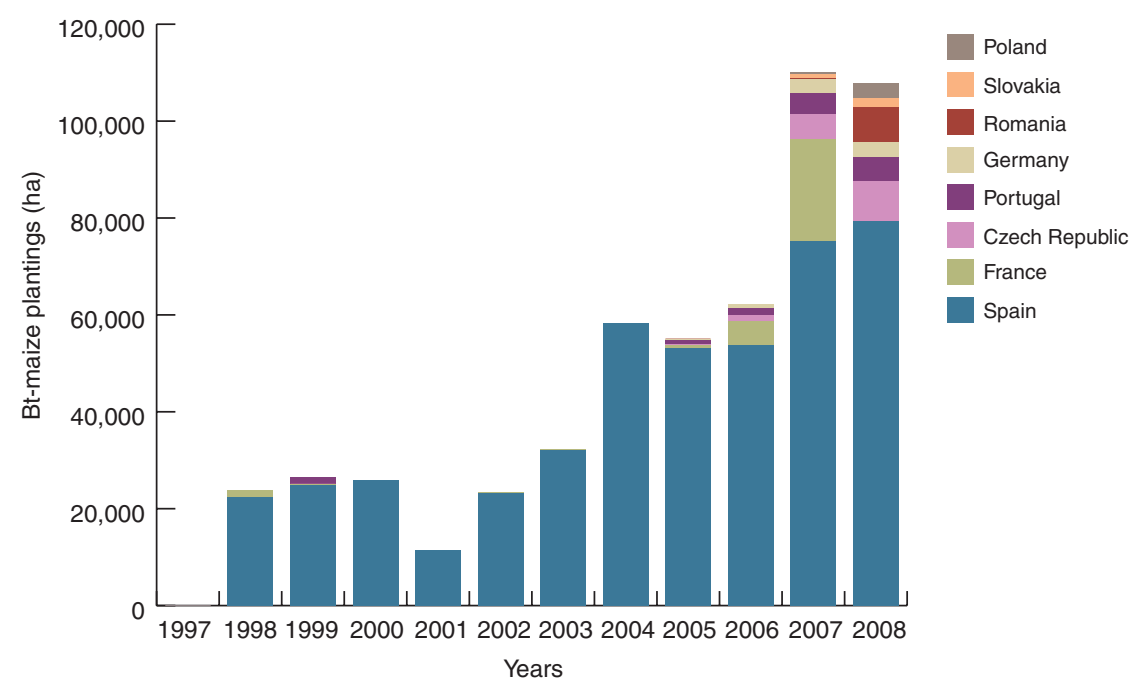

Figure 1 Cumulative Bt maize plantings (ha) per member state in the EU (1997-2008). In 2008, France banned the cultivation of maize MON810 on its territory. 


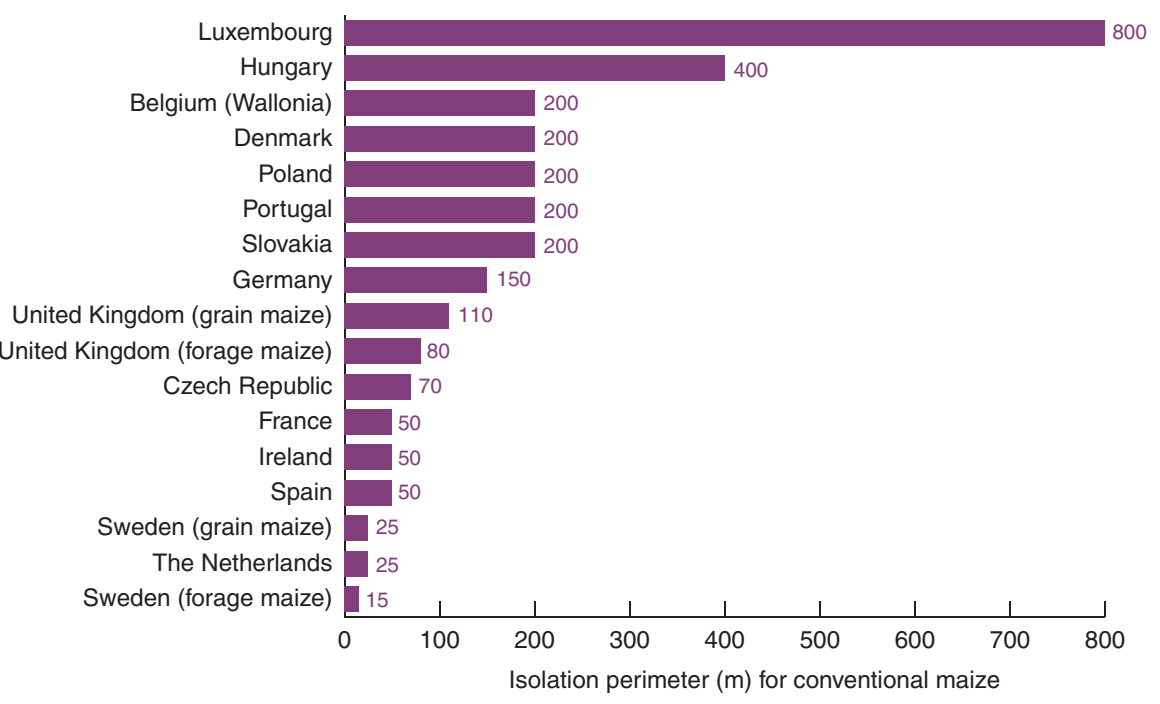

Figure 2 Isolation distances (m) proposed by European member states to ensure coexistence between GM and conventional non-GM maize (adapted from the EC's report on the implementation of national measures on the coexistence of GM crops with conventional and organic farming ${ }^{3}$ ). Isolation distances to organic farming are not shown.

to warrant that non-GM agricultural products comply with the legal tolerance threshold for the unintentional or technically unavoidable presence of approved GM material in non-GM products. If the content of GM material in a non-GM product exceeds the tolerance threshold, the product has to be labeled as containing GM material, which may affect its market acceptability. Because GM crops are judged to be safe before their commercial release, safety issues fall outside the remit of coexistence. In the EU, a tolerance threshold of $0.9 \%$ applies for food, feed and organic products, whereas no threshold is officially in place for seeds ${ }^{2}$. Contrary to ex ante coexistence regulations, expost liability schemes are backwardlooking: they cover questions of liability and the duty to redress the incurred economic harm once adventitious mixing has occurred.

In the case of maize, cross-fertilization due to pollen flow between neighboring fields represents the major potential biological source of on-farm (gene) mixing: maize is a cross-pollinated crop, relying on wind for the dispersal of its pollen. Although different preventive on-farm measures can be implemented, a report of the $\mathrm{EC}^{3}$ indicates that many member states are currently imposing or proposing isolation distances ranging between $15 \mathrm{~m}$ and $800 \mathrm{~m}$ as the sole means of keeping GM-inputs due to crossfertilizations below the tolerance threshold of $0.9 \%$ (Fig. 2). Because cross-fertilization levels rapidly decrease with increasing distance from the pollen source, spatially isolating GM maize from non-GM maize is an efficient measure to reduce the extent of cross-fertilization ${ }^{4,5}$. However, imposing wide and fixed isolation distances around GM maize fields entails four challenges to EU policymakers.

The first of these is appropriateness. A challenge that faces member states is how to define appropriate and thus scientifically defensible isolation distances. Crossfertilization studies mimicking worst-case on-farm situations demonstrated that in many cases isolation distances exceeding $50 \mathrm{~m}$ are not necessary to comply with the tolerance threshold of $0.9 \%$ in grain maize $^{4-7}$. Similar conclusions have been drawn from cross-fertilization studies performed under real agricultural situations in Spain $^{8}$ and from predictive vertical gene flow modeling at the landscape level in France ${ }^{9}$. Considering that cross-fertilization is only affecting maize kernels and that vegetative plant parts are unaffected, isolation distances for forage maize could be even shorter6.

A second challenge is how to propose feasible isolation distances that do not jeopardize farmers' freedom of choice to grow GM crops. Prospective case studies have shown that the implementation of wide isolation distances might not always be feasible, especially in areas where maize is grown on a substantial part of the agricultural area and/or where maize fields are small and scattered throughout the cropped area ${ }^{5,10,11}$. In these cases, it is highly probable that isolation perimeters would interfere with adjacent non-GM maize fields. If farmers do not concur with the respective cropping intentions of their neighbors, wide isolation distances might affect farmers' freedom of choice to grow GM maize, which contradicts European coexistence objectives.

Even if these first two challenges can be met, preventive coexistence measures must be defined that take into account the regional heterogeneity of farming. The enforcement of fixed isolation distances does not consider several factors that influence cross-fertilization (e.g., regional heterogeneity in $B t$ maize share, cropping patterns, field characteristics and distribution). Currently proposed fixed isolation distances were mostly derived from studies performed under worst-case situations. Because such situations might not often arise in practice, fixed isolation distances can be unnecessarily conservative. In real agricultural conditions, fields are planted with GM and non-GM maize varieties with different sowing or flowering dates, and agricultural landscapes comprise a mix of maize fields, other crops and physical and/or natural barriers ${ }^{5,8,10}$.

A last challenge is that of proportionality. EU policymakers must define preventive coexistence measures that are proportional to economic incentives and that do not impose an excessive burden on EU farmers. Coexistence is only relevant when there are economic incentives for farmers to supply both GM and non-GM maize ${ }^{12,13}$. Economic incentives for coexistence are either (i) the adoption of $B t$ maize to capture 'GM gains' or (ii) the cultivation of GM-free crops for capturing 'GM-free gains'. GM gains include productivity and efficacy increases, production cost reductions, as well as nonpecuniary benefits. Compared with non-GM maize in areas where infestation of the European and Mediterranean corn borer is high, economic benefits of $B t$ maize consist of (i) higher yield levels, (ii) lower pesticide usage, (iii) lower pest damage resulting in decreased levels of mycotoxins and therefore (iv) enhanced safety and quality for animal and human consumption ${ }^{14,15}$. Conversely, GM-free gains center around the total additional income generated by price premiums for non-GM crops compared with GM crops.

A key issue is that if non-GM crop products were admixed with GM crop products at levels above the EU tolerance threshold, such 
crops would forfeit their 'GM-free' status and would therefore have to be commercialized as containing GM material at the same price as GM crops, thus losing their market price premium. In contrast, the presence of GMfree grains in GM crop batches would have no penalty for farmers of those varieties.

Farmers cultivating non-GM maize would thus only have an incentive to preserve the 'non-GM' status of their production by applying coexistence measures if consumers have (i) strong and sustainable preferences for non-GM maize and (ii) are willing to pay significant price premiums for it. In markets where consumers are unwilling to pay significant price premiums for GM-free maize, there is no coexistence issue stricto sensu. Under market conditions where hardly any GMfree gains can be captured, wide and fixed isolation distances may generate substantial opportunity costs for maize producers who forego GM gains due to proximity to non-GM maize fields, and who are 윽 hardly capturing any compensatory GM-free gains. Moreover, this loss is not proportional to the weak incentives to supply non-GM crops and to ensure coexistence with non-GM crops $^{12,13}$.

Taken together, we conclude that wide and fixed isolation distances, as currently proposed by many member states, fail to satisfy several challenges. First, they are excessive from a scientific point of view; second, they are difficult to implement in practice; third, they are inconsistent (3) with regional heterogeneity of farming; the economic incentives for coexistence. To enable regionally and economically proportionate coexistence, policymakers should allow integrating flexibility in ex ante coexistence regulations. This might be achieved by allowing plural coexistence measures that are adaptable to local farming and cropping conditions, and that are negotiable among farmers. Computerbased decision support tools may thereby play a crucial role in the future case-bycase-based coexistence approach, as they allow the prediction of achievable levels of coexistence between neighboring maize fields under various conditions ${ }^{16}$. One caveat here is that policymakers may be reluctant to adopt such a case-by-case coexistence approach because of the difficulties of implementation.

The irony is that the adopted coexistence policy initially contributed to the lifting of the EU moratorium, whereas currently it is placing another barrier on the path of GM crops. In some EU regions, there seems to be low or no political willingness to tolerate any adventitious mixing from $B t$ maize. To comply with their zero-tolerance policy, these regions impose wide and fixed isolation distances as sole preventive measure in ex ante coexistence regulations. This could be interpreted as a return or even a continuation of the lifted moratorium at the national/regional level. Without a strong signal from the EC to incite member states to build in flexibility in national/ regional coexistance regulations, the future of GM crop production might be further jeopardized in the EU.

\section{DISCLAIMER}

Opinions and views expressed in the present correspondence letter are strictly those of the authors, and do not represent those of the organizations where the authors are currently employed.

Yann Devos ${ }^{1}$, Matty Demont ${ }^{2,3}$ \& Olivier Sanvido 4

${ }^{1}$ Department of Plant Production, Faculty of Bioscience Engineering, Ghent University, Coupure Links 653, 9000 Ghent, Belgium. ${ }^{2}$ Africa Rice Center (WARDA), Senegal, Africa. ${ }^{3}$ Centre for Agricultural and Food Economics, Katholieke Universiteit Leuven, Belgium. ${ }^{4}$ Agroscope Reckenholz Tänikon Research Station ART, Switzerland.

e-mail:Yann.Devos@efsa.europa.eu

1. European Commission. Off. J. Eur. Union L189, 36-47 (2003).

2. European Commission. Off. J. Eur. Union L268, 1-23 (2003).

3. http://ec.europa.eu/agriculture/coexistence/sec313_ en.pdf

4. Devos, Y., Reheul, D. \& De Schrijver, A. Environ. Biosafety Res. 4, 71-87 (2005).

5. Sanvido, 0. et al. Transgenic Res. 17, 317-335 (2008).

6. Weber, W.E. et al. J. Agron. Crop Sci. 193, 79-92 (2007).

7. Weekes, R. et al. Transgenic Res. 16, 203-211 (2007).

8. Messeguer, J. et al. Plant Biotechnol. J. 4, 633-645 (2006).

9. http://ftp.jrc.es/EUR22102en.pdf

10. Devos, Y. et al. Agron. Sustain. Dev. 28, 195-206 (2008).

11. Perry, J.N. Proc. R. Soc. Lond. B 269, 1173-1176 (2002).

12. Demont, M. et al. Ecol. Econ. 64, 683-689 (2008).

13. Demont, M. \& Devos, Y. Trends Biotechnol. 26, 353-358 (2008).

14. Gómez-Barbero, M., Berbel, J. \& Rodríguez-Cerezo, E. Nat. Biotechnol. 26, 384-386 (2008).

15. Wu, F. Transgenic Res. 15, 277-289 (2006).

16. Beckie, H.J. \& Hall, L.M. Plant Sci. 175, 615-628 (2008). 